\title{
A Narrative Synthesis of Childhood Injury Prevention Programs for Pre-school Children
}

\author{
Blake Peck $^{1, *}$, Daniel Terry ${ }^{1}$, Kaye Ervin ${ }^{2}$ \\ ${ }^{1}$ School of Health, Federation University, Australia \\ ${ }^{2}$ Faculty of Medicine, Dentistry and Health Sciences, The University of Melbourne, Australia
}

Received July 13, 2020; Revised September 4, 2020; Accepted September 17, 2020

\section{Cite This Paper in the following Citation Styles}

(a): [1] Blake Peck, Daniel Terry, Kaye Ervin , "A Narrative Synthesis of Childhood Injury Prevention Programs for Pre-school Children," Universal Journal of Public Health, Vol. 8, No. 6, pp. 193 - 197, 2020. DOI: 10.13189/ujph.2020.080602.

(b): Blake Peck, Daniel Terry, Kaye Ervin (2020). A Narrative Synthesis of Childhood Injury Prevention Programs for Pre-school Children. Universal Journal of Public Health, 8(6), 193 - 197. DOI: 10.13189/ujph.2020.080602.

Copyright@2020 by authors, all rights reserved. Authors agree that this article remains permanently open access under the terms of the Creative Commons Attribution License 4.0 International License

\begin{abstract}
Childhood injury is the leading cause of death and ongoing disability worldwide. While a cornerstone of injury prevention is education, current injury surveillance data is insufficiently nuanced to inform judgement of their effectiveness. A subsequent dearth of research evidence in the domain of childhood injury means that debate continues in regard to the most appropriate age or developmental stage of the child, as well as the most effective pedagogical approach. When considered together these issues culminate in programs that risk being inadequately targeted that are unable to justify their success in reducing injury and consequently are not sustainable. This paper reports the outcomes of a narrative synthesis approach to the review of literature in the area if childhood injury prevention programs targeted at pre-school children. Three studies met the inclusion criteria. The included studies were of poor quality and lacked convincing evidence of effectiveness due to the methods of evaluation, which in turn have shown to impact on the overall sustainability of each specific program. This paper culminates in recognition that there is insufficient evidence of the effectiveness of childhood injury prevention programs for pre-school children, requiring further high-quality studies to determine their overall effectiveness and longer-term sustainability.
\end{abstract}

Keywords Childhood Injury, Narrative Synthesis, Unintentional Injury, Pre-school Children, Programs

\section{Introduction}

Injuries are a major killer of children globally, with over 2000 children and teenagers dying daily from an injury [1]. There are multiple childhood injury prevention programs in existence, which range from parental education to programs targeting various age groups, predominantly school age children and teenagers. The fact that childhood injury rates declined globally between 1990 and 2013 Huang et al. [1], suggest that injury prevention programs, coupled with legislation, such as child safety seats, are effective. Preventing injuries in children is important, not only because they are so common, but because the effects on the child and family can be severe and long lasting [2]. The challenge for programs targeting children is the need to tailor interventions to the developmental age of the child [3]. To effectively assess injury prevention programs, the impact of interventions must be measured as accurately, consistently, and comprehensively as possible [4].

We reviewed the literature on childhood injury prevention programs with an aim of determining their effectiveness as the primary goal. Our secondary goal was to determine sustainability of such programs aimed at children. Our interest was in the pre-school age group.

There are a number of ways in which research evidence can be brought together and used to inform policy and practice. Systematic reviews, considered the 'gold standard', focus on the effectiveness of interventions and often include meta-analysis of the data from numerous studies [5]. Systematic reviews, as the name suggests, largely describe a systematic approach to searching the 
literature and include an appraisal of the research evidence in a transparent process aimed at avoiding bias. Such reviews rely on high quality research evidence, most often of a quantitative nature.

Narrative synthesis refers to an approach undertaken to systematically search the literature and synthesise the findings primarily using words and texts to summarise and explain the findings [6]. Narrative synthesise allows the inclusion of various methodologies not limited to quantitative techniques.

\section{Objective}

We undertook a search of the literature to explore the evidence for childhood injury prevention programs for pre-school children. We were interested in all studies that described programs or interventions targeted at pre-school children. Our objective was to examine the effectiveness of such programs with a secondary goal of determining sustainability of childhood injury prevention programs, using a narrative approach.

\section{Methods}

We followed the guidance on conduct of narrative synthesis described by Ryan [7]. Two researchers, BP and DT conceived the study and BP, DT and KE determined the eligibility criteria. The search of databases was to include all study methodologies and focus on injury prevention initiatives for children 0-6 years of age. The search was limited to English publications between 2008 to 2019 to provide a contemporary view. The study protocol was not registered.

An initial Google search was undertaken in August 2019 using the term 'Childhood injury prevention programs' to explore articles, websites and policy documents for alternative terms used that may be relevant. Data bases searched in August and October of 2019 were limited to CINAHL, Medline, psychINFO, EMBASE, ERIC and Cochrane Library.

Search terms included (child* OR paediatric OR kids) AND (prevent* OR safety) AND (injury OR unintentional injury OR accident* OR risk* OR trauma*) AND (program* OR education OR community OR enablers).

Exclusion criteria included studies related to violence, abuse or neglect, studies that focused exclusively on adolescents or children aged greater than 6 years, the development of legislation, mortality or prevalence, environmental pollutants or rehabilitation as this was not our focus.

Data extraction was performed by KE and included the population of the study, country where the study was conducted, the study type, the intervention and the major finding of the study. Where there was uncertainty, BP screened the studies under consideration, for discussion with $\mathrm{KE}$ to decide inclusion or exclusion. Relevance to the study question was the overarching inclusion criteria. For feasibility, the search was limited to medical and allied health data bases with only one education data base (ERIC).

\section{Results}

The search returned 122 studies, after removing 20 duplicates, an examination of the titles to determine the focus of the study excluded a further 46 studies. The abstracts of 56 articles were initially screened and a further 12 excluded as either not being focused on unintentional injury program or interventions, or not being an actual piece of research and instead being a quality improvement or descriptive piece of work. The full text of 44 articles were read, 31 did not meet the eligibility criteria for age and for three studies the age of the children could not be determined. Of these 44 studies, a further 10 studies focused on the parent not the child or the study focused heavily on the methodology of evaluation not the intervention itself. A final three studies were selected for the synthesis. These studies were critically appraised using the appropriate CASP checklists [8] for methodological rigour and bias. The study selection is shown in Figure 1 using the PRISMA flow chart [9].

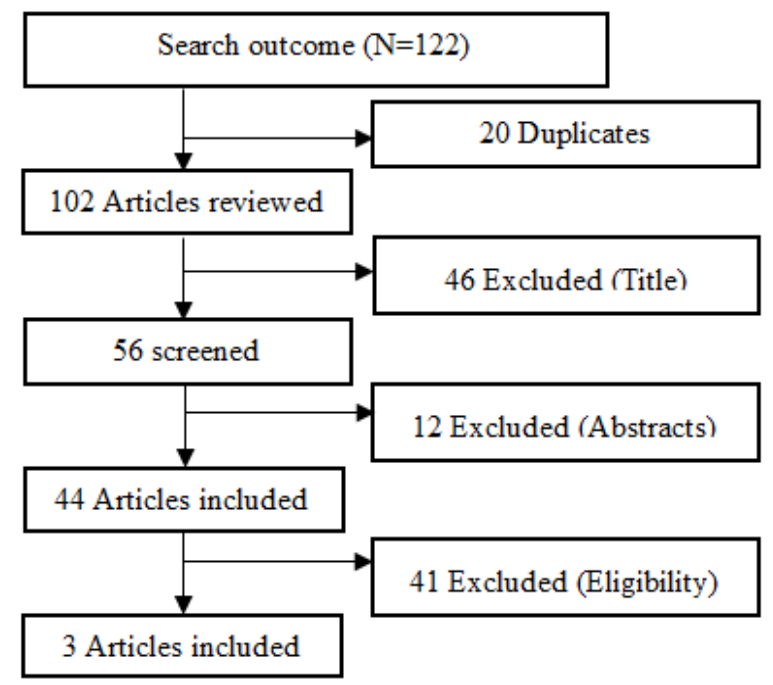

Figure 1. Study selection

The synthesis was limited to three studies that focused on pre-school children and included some degree of evaluation. The literature related to childhood injury concerned studies overwhelmingly targeted at older aged children and teenagers or the parents of younger children. The studies selected are shown in Table 1, including the population under study, the country where it was conducted, the study methodology, the intervention used in the study and the major findings.

While not anticipated, all of the studies finally shortlisted were published in the same journal - the Journal of Trauma Nursing. In addition, all three studies were conducted in the USA. 
Table 1. Studies included in the synthesis

\begin{tabular}{|c|c|c|c|}
\hline Study & $\begin{array}{c}\text { Country and study type } \\
\text { and population }\end{array}$ & Intervention & Findings \\
\hline $\begin{array}{c}\text { Elwell,S., Kulp, H., McCue, J. (2014). } \\
\text { Creating a comprehensive bicycle safety } \\
\text { program. Journal of Trauma Nursing.[12] }\end{array}$ & $\begin{array}{c}\text { USA } \\
\text { Descriptive } \\
\text { Children 3-18yrs }\end{array}$ & $\begin{array}{c}\text { Multi-pronged } \\
\text { education program }\end{array}$ & $\begin{array}{c}\text { No evaluation but some evidence } \\
\text { of improved knowledge }\end{array}$ \\
\hline $\begin{array}{c}\text { Emery, K., Hawkes, A., Cassabaum, V., } \\
\text { Rapstine, T. (2010). Junglemobile: A }\end{array}$ & $\begin{array}{c}\text { USA } \\
\text { Quantitative } \\
\text { Mobile Injury-Prevention Program for } \\
\text { young Children. Journal of Trauma } \\
\text { Nursing. [10] }\end{array}$ & $\begin{array}{c}\text { Evaluation of the } \\
\text { Junglemobile child } \\
\text { passenger safety } \\
\text { program }\end{array}$ & $\begin{array}{c}\text { Significant improvement in } \\
\text { ability to demonstrate safe place } \\
\text { to ride in a car (3-6 yr old) and } \\
\text { improvement in use of restraint } \\
\text { (7-10 yr old) }\end{array}$ \\
\hline $\begin{array}{c}\text { Schooley, } \text { yrs and } \\
\text { hazards: can children recognize the }\end{array}$ & $\begin{array}{c}\text { USA } \\
\text { Quantitative }\end{array}$ & $\begin{array}{c}\text { Hazard identification } \\
\text { program }\end{array}$ & $\begin{array}{c}\text { Education about safety should be } \\
\text { directed at }<10 \text { age group } \\
\text { Overall } 80 \% \text { recognised 50\% of } \\
\text { the hazards }\end{array}$ \\
\hline
\end{tabular}

\subsection{Age of Children and Number of Participants}

In all the included studies the interventions were not exclusively for pre-school children, but included pre-school age children in their target population. Emery et al [10], included two cohorts, a 3-6-year-old cohort and a 7-10 year old cohort. Schooley and Kelly [11], also included older age groups, up to 17 years as did Elwell et al [12]. Elwell et al do not specify the number of participants exposed to their multi-pronged interventions, or the number of participants of pre-school age. Emery et al [10] specify that there were 104 participants aged five and under, with the remainder (133) in the aged six to 10 years. Schooley and Kelly's [11] study does not specify the total number of participants in each age group, but does specify results by age, which includes three, four and five year old children.

\subsection{Intervention and Outcomes}

Two of the studies $[10,11]$ used a quantitative approach and the remaining paper [12] was descriptive with little evaluation. The intervention in the study conducted by Elwell et al [12], was nine age-appropriate programs focused on bicycle safety and helmet use. The project stemmed from a paediatric trauma centre where $5 \%$ of all injuries were bicycle related. One age-specific intervention was a book program which was implemented in pre-schools in which an interactive book about bicycle safety and helmet use was read aloud, with children participating in the story. Another intervention entitled 'caught you being safe' involved local businesses and law enforcement officers providing vouchers to children who were observed obeying bicycle safety laws to serve as positive reinforcement. A helmet program included distribution of free bicycle helmets, low cost community helmet sales and a helmet consult for patients admitted to the emergency department (which included a free helmet correctly fitted and educational materials). A safety award was also initiated which involved an award to patients involved in an accident but wearing a safety helmet. Three other interventions in the same program (a classroom educational program, a video game for 7-11 year olds and a bike rodeo for 7-10 year olds) involved older children who were not our target group. While the authors stated that the intervention played a key role in injury prevention, there was no evaluation or evidence presented to support this.

Schooley and Kelly [11] used a quantitative approach to test children in recognising home hazards. Children were walked through a simulated home with three rooms which contained various hazards, such as pot handles hanging over the edge of a stove, a toaster with a knife in the bread slot, pills in an open container etcetera. The children were instructed to walk through and note safety problems while a researcher ticked off a tally sheet. Their findings showed that children aged 6 years and younger identified $50 \%$ of the hazards. There was a correlation between age and hazard identification, identification results rose in relation to age of the child. Children who missed hazards were walked through again and the hazards were explained to them. The researchers excluded 23 participants because of parent or sibling assistance in identifying hazards.

The study by Emery et al [10] involved two participant age groups, 3-6 years and 7-10 years and utilised a pre and post-test quantitative design. Children were asked to circle a picture that showed the correct way to be in a car seat and used a doll to demonstrate the safest place to travel in a car. The intervention involved a mobile safety van visiting community that showed children the correct way to wear a safety belt and the safest position to sit in a car, as well as education on other safety issues. For the 3 -6-year age group over $95 \%$ of children were able to circle the correct way to be buckled into a car pre-test, so post test showed no improvement. There was a statistically significant improvement in knowledge of where to travel in a car (69\% pre-test to $86 \%$ post-test), following the intervention. The researchers state that care was taken not to prompt children during the test. Older children underwent more testing and follow up testing but this was not extended to the 3-6 year age group. 


\subsection{Bias}

The three selected articles were published in the same journal. There were 18 articles that the authors deliberated over for exclusion or inclusion that represented eleven different journals, suggesting that the Journal of Trauma Nursing is biased towards studies representing injury prevention in younger age groups. Additionally, only studies from the USA were included and the interventions may not be applicable to other countries.

\subsection{Synthesis of Studies}

The three studies [10-12] described disparate interventions and methods of evaluation, although all included pre-school aged children. All three studies described injury prevention interventions in communities. Elwell et al [12] claim improved knowledge of children resulted from the intervention, but show little evidence of evaluation, apart from providing positive quotes from community members. Attempts to contact the authors for further information was not successful. Both other studies $[10,11]$ demonstrate that pre-school children can recognise hazards. All of the studies lacked rigorous, convincing evidence. Elwell et al [12] acknowledge the lack of evaluation in their study and cite future plans to create an evaluation tool to measure effectiveness and to examine local and state trauma registries. Schooley and Kelly [11] and Emery et al [10] provide the most convincing results presenting evidence of statistical significance and evidence that they controlled for bias (excluding results that had parental assistance and taking care not to lead children in their answers).

\section{Discussion}

Previous research has shown that pre-school children do comprehend and develop safety awareness. For example, a historical study on firearm safety [13] showed that five-year olds exhibited a large increase in safety knowledge when age appropriate interventions were tested. Another study that tested children's understanding of safety signs [14] in 7-10 year olds recommended testing in younger age groups, as did one of the studies [11] included in the synthesis. O'Neill's Australian studies [15, 16] support the finding that pre-school children do comprehend safety messages, providing evidence that injury prevention programs should begin in younger aged cohorts of children. Despite this, there is a dearth of research evidence that focuses specifically on childhood injury prevention programs targeted at pre-school children. Much of the literature for injury prevention in the 0-6 years age group has a parental education intervention [17-19]. This is understandable, given that injury risks to toddlers can be a result of parental neglect to control risks [1]. However, a great deal of interventions aimed at injury prevention for pre-school children, appear to overlook the capacity of this age group to build safety risk intelligence that equips them with capabilities they need to become competent risk-takers and manage their safety in everyday life and activities [17].

The studies included in the synthesis were predominantly poor quality and failed to show convincing evidence of effectiveness. This is perhaps because evaluation of such programs requires longitudinal study methods to assess effectiveness, which is often untenable if the program receives fixed term funding. In addition, the most convincing measure of effectiveness is a reduction in childhood injury rates in the area under study. This measure would require a comprehensive childhood injury register and rely on rigorous reporting and controls for population changes, which is both expensive and potentially unreliable. Reliability of such a register would require health professionals to discern between unintentional versus intentional injury of children.

\section{Limitations}

Given the limitations of language of the authors, only articles published in English were included which means we may have missed other important studies. The search of data bases was not exhaustive and predominantly limited to health sciences, so studies published in other disciplinary domains may have been missed.

\section{Conclusions}

There is a scarcity of high quality studies on the effectiveness of childhood injury prevention for pre-school children. With childhood injury posing a significant public health burden, there is a growing need to better understand the role that injury prevention programs are having on reducing injury and promoting safety. As younger children are capable of increasing their safety awareness, our understanding of ever better ways to provide effective and sustainable programs is essential to reduce the long-term burden on the child, their family and wider society.

\section{REFERENCES}

[1] Huang Y., Wu Y., D. Schwebel, et al. "Disparities in Under-Five Child Injury Mortality between Developing and Developed Countries: 1990-2013”, Environmental Research and Public Health. 2016.

[2] Orton E., Whitehead J., Mhizha-Murira J., et al. "School-based education programmes for the prevention of unintentional injuries in children and young people (Review)", Cochrane Database of Systematic Review, Vol.12, 2016. 
[3] Morrongiello B., D. Schwebel, "Gaps in childhood injury research and prevention: What can developmental scientists contribute? Child development Perspectives”, Vol.2, 78-84. 2008.

[4] Pankratz C., Lynne Warda L., C. Piotrowski, “Challenges in the Accurate Surveillance of Booster Seat and Bicycle Helmet Usage by Children: Lessons from the Field", Environmental Research and Public Health. 2016.

[5] Liberati A., Altman D., Tetzlaff J., et al. “The PRISMA statement for reporting systematic reviews and meta-analysis of studies that evaluate health care interventions: Explanation and elaboration”, PLoS Medicine Vol.6, No.7. 2009.

[6] Karolina L., K. Porritt, “Narrative Synthesis. Considerations and Challenges”, International Journal of Evidence-Based Healthcare Vol.14, No.10, 2016.

[7] Ryan, R., "Cochrane Consumers and Communication Review Group: data synthesis and analysis", Cochrane. Consumers and Communication. 2013.

[8] Public Health Resource Unit. CASP. Critical Appraisal Skills Programme, 2008.

[9] Moher D., Liberati A., J. Tetzlaff., et al. "Preferred Reporting Items for Systematic Reviews and Meta-Analyses: The PRISMA Statement”, PLoS Medicine Vol.6, No. 6. 2009.

[10] Emery K., Hawkes A., V. Cassabaum, et al. “Junglemobile: A Mobile Injury-Prevention Program for young Children”, Journal of Trauma Nursing, January-May. 2010.

[11] Schooley C., A. Kelly, "Home hazards: Can children recognize the dangers?” Journal of Trauma Nursing, Vol.15, No.3, 2008.
[12] Elwell S., Kulp H., J. McCue. “Creating a comprehensive bicycle safety program”, Journal of Trauma Nursing, Vol.21, No.6, 2014.

[13] Kunz Howard P., "Evaluation of Age-Appropriate Firearm Safety Interventions”, Pediatric Emergency Care, Vol.21, No.7. 2005.

[14] Morrongiello B., Cox A., R. Scott., et al. "Children's understanding of no diving warning signs: Implications for preventing childhood injury”, Environmental Research and Public Health, Vol.13. 2016.

[15] S. O’Neill. Safety risk intelligence: Children's concept formation of safety and their individual capabilities to appraise risk of injury, Australasian Journal of Childhood Development, Vol.41, No.2. 2016.

[16] O’Neill S., Fleer M., J. Agbenyega., et al. “A cultural-historical construction of safety education programs for preschool children: Findings from SeeMore Safety, the pilot study", Australasian Journal of Childhood Development, Vol.38, No. 2, 2013.

[17] Chandran A., Khan U., N. Zia, et al. "Disseminating childhood home injury risk reduction information in Pakistan: Results from a community based pilot study". Environmental Research and Public Health, Vol.10, 2013.

[18] Clapham K., Bennett-Brook K., K. Hunter. "The role of aboriginal workers in delivering a child safety-focused home visiting program for Aboriginal families in an urban region of New South Wales", Health Promotion Journal of Australia Vol.29, 2017.

[19] Weaver N., Williams J., H. Jacobsen, et al. "Translation of an evidence-based tailored childhood injury prevention program”, Journal of Public Health Management Practice, Vol.14, No.2., 2008. 